\title{
SOLUTIONS AND STABILITY ANALYSIS OF BACKWARD-EULER METHOD FOR SIMPLIFIED MAGNETOHYDRODYNAMICS WITH NONLINEAR TIME RELAXATION
}

\author{
Gamze YÜKSEL*, Department of Mathematics, Faculty of Science, Muğla Sitkı Koçman University, Turkey, ngamze@mu.edu.tr \\ (iD) https://orcid.org/0000-0003-3578-2762) \\ Mustafa Hicret YAMAN, Department of Mathematics, Faculty of Science, Muğla Sitkı Koçman University, Turkey \\ hicretyaman@gmail.com \\ (iD) https://orcid.org/0000-0001-6483-0140) \\ Received: 04.05.2021, Accepted: 03.12.2021 \\ *Corresponding author \\ DOI: $10.22531 /$ muglajsci.932484
}

\begin{abstract}
In this study, the solutions of Simplified Magnetohyrodynamics (SMHD) equations by finite element method are examined with nonlinear time relaxation term. The differential filter $\kappa(|u-\bar{u}|(u-\bar{u}))$ term is added to SMHD equations. Also SMHD Nonlinear Time Relaxation Model (SMHDNTRM) is introduced. The model is discretized by Backward-Euler (BE) method to obtain the finite element solutions. Moreover, the stability of the method is proved. The method is found unconditionally stable. The effectiveness of the method is exemplified by several cases with comparing different methods. FreeFem++ is used for all computations.

Keywords: MagnetoHydroDynamics, Backward-Euler Method, Nonlinear Time Relaxation, Finite Element Method

\section{DOĞRUSAL OLMAYAN ZAMAN RAHATLAMALI BASITTLŞTIIIİLMIŞ MANYETOHİDRODİNAMIKLER İÇİN BACKWARD-EULER YÖNTEMİ ÇÖZÜMLERİ VE KARARLILIK ANALİZI}

\begin{abstract}
Özet
Bu çalışmada, Basitleştirilmiş Manyetohidrodinamik (SMHD) denklemlerinin sonlu elemanlar yöntemiyle çözümleri lineer olmayan zaman rahatlatma terimi ile incelenmiştir. SMHD denklemlerine diferansiyel filtre $\kappa(|u-\bar{u}|(u-\bar{u}))$ terimi eklenmiş ve SMHD Lineer Olmayan Zaman Rahatlatma Modeli (SMHDNTRM) tanıtılmıştır. Model, sonlu elemanlar çözümlerinin elde edilmesi için Backward-Euler (BE) yöntemi ile ayrıklaştırılmıştır. Yöntemin kararlılı̆̆ı da kanıtlanmıştır. Sunulan yöntem koşulsuz olarak kararlıdır. Yöntemin etkinliği, farklı yöntemlerin karşılaştırılmasıyla birkaç örnek ile gösterilmiştir. Tüm hesaplamalar FreeFem++ kullanılarak yapılmıştır.

Anahtar Kelimeler: MagnetoHydroDynamics, Backward-Euler Method, Nonlinear Time Relaxation, Finite Element Method Cite

Yüksel, G., Yaman, M, H., (2021). "Solutions and Stability Analysis of Backward-Euler Method for Simplified Magnetohydrodynamics with Nonlinear Time Relaxation”, Mugla Journal of Science and Technology, 7(2), 45-51.
\end{abstract}

\section{Introduction}

MagnetoHydroDynamics (MHD) deals with mostly dynamics of magnetic fields for electrically conducting fluids, such as plasmas and liquid metals. The MHD modeling consists of a coupling between the NavierStokes equations of fluid dynamics and the Maxwell equations of electromagnetism. The theoretical analysis and mathematical modeling of the MHD equations can be found in [1]. When magnetic Reynolds number $R_{m}$ is small, the induced field being negligible by comparison with the imposed field. In this case the magnetic field behaves quite differently. For example, in most experiments or industrial process $R_{m}$ changes between 0.001 to 0.1 . Magnetic damping of jets, vortices or turbulence, magnetic stirring using a rotating magnetic field, magnetic levitation are typical examples of this [1]. The simplified MHD is obtained by eliminating magnetic Reynolds number. Thus, fluid and magnetic equations are uncoupled in MHD. The existence and uniqueness of the weak form of simplified MHD (SMHD) is introduced by Janet Peterson in [2]. In that paper, a finite element algorithm is also given for the approximate solution of the SMHD. There are several paper for numerical solutions of MHD with small $R_{m}$ in literature. The stability analysis of partitioned methods for MHD at small magnetic Reynolds number is presented by Layton et al. in [3]. Numerical analysis of finite element method with Crank-Nicolson discretization [4] and Backward-Euler discretization [5] are performed by Yuksel et. al. for SMHD. Numerical analysis of two partitioned methods for uncoupling 
evolutionary MHD flows are presented in [6]. A second order algorithm is performed by Rong et al in [7].

We consider a time relaxation regularization which is obtained by adding nonlinear time relaxation term to the SMHD in the current paper. The time relaxation operator is introduced as a numerical regularization in $[8,9,10,21]$ which are based on the study Chapman-Enskog expansions by Rosenau [11], Schochet and Tadmor [12]. In [13], studies are summarized for development and implementations of time relaxation and time relaxation models. In their studies Brekling and his colleagues show that these techniques can be used to advance the accuracy and stability of fluid flow problems with higher Reynolds numbers. In [14], Pakzad examines time averaged energy dissipation rate for the Time Relaxation Model for $3 \mathrm{~d}$ turbulence with periodic boundary conditions. The studies about the time relaxation regularization can be found in the literature, such as $[15,16,17]$. The effects of the linear and nonlinear time relaxation terms to SMHD equations with BE finite element method is presented in [18].

In this paper, SMHD equations are handled with nonlinear time relaxation term to get more accurate solutions. The stability analysis is also conducted. The unconditionally stability of the method is proved. In the numerical examples the effectiveness of the method is presented. The solutions of the present method are compared with $\mathrm{BE}$ and $\mathrm{CN}$ solutions for SMHD and BE solutions for SMHD with linear time relaxation model (SMHDLTRM).

SMHDNTRM is obtained by adding the nonlinear term $\kappa(|\mathrm{u}-\overline{\mathrm{u}}|(\mathrm{u}-\overline{\mathrm{u}}))$ into SMHD as follows

$$
\begin{aligned}
N^{-1}\left(u_{t}+u \cdot \nabla u\right) & \\
& =f+M^{-2} \Delta u-\nabla p+B \times \nabla \phi \\
& +(u \times B) \times B \\
\nabla \cdot u & =0
\end{aligned}
$$

$-\Delta \phi+\nabla \cdot(u \times B)=0$.

where $\kappa, \delta>0$ and $u$ is the unique solution of

$$
\begin{gathered}
\bar{u}_{t}=\frac{|u-\bar{u}|(u-\bar{u})}{\delta}, t>0 \\
\bar{u}(x, 0)=u(x, 0) .
\end{gathered}
$$

Let $\Omega \subset \mathbb{R}^{d}(\mathrm{~d}=2$ or 3 ) be an open, regular domain. The dimensionless quasi-static MHD is modelled by the system, see, e.g., [4]: Given time $\mathrm{T}>0$, body force $f$, interaction parameter $N>0$, Hartmann number $M>0$,

and letting $\Omega_{T}:=[0, T] \times \Omega$, find velocity $u: \Omega_{T} \rightarrow \mathbb{R}^{d}$, pressure $p: \Omega_{T} \rightarrow \mathbb{R}$, electric current density $j: \Omega_{T} \rightarrow \mathbb{R}^{d}$, magnetic field $B: \Omega_{T} \rightarrow \mathbb{R}^{d}$, and electric potential $\varphi: \Omega_{T} \rightarrow$ $\mathbb{R}$ satisfying

$$
\begin{gathered}
N^{-1}\left(u_{t}+u \cdot \nabla u\right)=f+M^{-2} \Delta u-\nabla p+j \times B, \\
\nabla \cdot u=0 \\
-\Delta \phi+\nabla \cdot(u \times B)=0, \quad \nabla \cdot j=0
\end{gathered}
$$

$$
\nabla \times B=R_{m} j, \quad \nabla \cdot B=0
$$

subject to boundary and initial conditions,

$$
\begin{aligned}
& u(x, t)=0, \quad \forall(x, t) \in \partial \Omega \times[0, t] \\
& \phi(x, t)=0, \quad \forall(x, t) \in \partial \Omega \times[0, t] \\
& u(x, 0)=u_{0}(x), \quad \forall x \in \Omega .
\end{aligned}
$$

Here, $R_{m}=U L / \eta>0, \mathrm{U}$ is the characteristic speed, $\mathrm{L}$ is the length of the problem, $\eta>0$ is the magnetic diffusivity, $u_{0} \in H_{0}^{1}(\Omega)^{d}$ and $\nabla \cdot u_{0}=0 . j$ and $\nabla \times B$ in (3) decouple $R_{m} \ll 1$. Supposing B is a magnetic field that is applied (and known), (3) reduces to the SMHD system see, e.g., [4]:

We examine full-discretization through Backward-Euler (BE) time-stepping of the SMHDNTRM. Let $0=t_{0}<t_{1}<$ $\cdots<t_{K}=T<\infty$ be a discretization of the time interval $[0, T]$ for a constant time step $\Delta t=t_{n}-t_{n-1}$. Write $z_{n}=$ $z\left(t_{n}\right)$. The weak form of the SMHDNTRM is presented in the following algorithm.

\section{Algorithm 1 (Backward-Euler Method for SMHDNTRM)}

Given $u_{0} \in V$, find $\left(u_{n+1}^{h}, p_{n+1}^{h}, \phi_{n+1}^{h}\right) \in X^{h} \times Q^{h} \times S^{h}$ for each $n=0,1,2, \ldots, K-1$, satisfying

$$
\begin{gathered}
N^{-1}\left[\left(\frac{u_{n+1}^{h}-u_{n}^{h}}{\Delta t}, v^{h}\right)+b^{*}\left(u_{n+1}^{h}, u_{n+1}^{h}, v^{h}\right)\right] \\
+M^{-2}\left(\nabla u_{n+1}^{h}, \nabla v^{h}\right)-\left(p_{n+1}^{h}, \nabla \cdot v\right) \\
+\left(-\nabla \phi_{n+1}^{h}\right. \\
\left.+u_{n+1}^{h} \times B_{n+1}, v^{h} \times B_{n+1}\right) \\
+\kappa\left(\left|u_{n}^{h}-\bar{u}_{n}^{h}\right|\left(\bar{u}_{n+1}^{h}-\bar{u}_{n}^{h}\right), v^{h}\right) \\
=\left(f_{n+1}, v^{h}\right), \quad \forall v \in X^{h} \\
\left(\nabla \cdot u_{n+1}^{h}, q\right)=0, \quad \forall q \in Q^{h} \\
\left(\nabla \phi_{n+1}^{h}-\left(u_{n+1}^{h} \times B_{n+1}\right), \nabla \psi\right)=0, \quad \forall \psi \in S^{h} \\
\frac{\bar{u}_{n+1}^{h}-\bar{u}_{n}^{h}}{\Delta t}=\frac{u_{n+1}^{h}-\bar{u}_{n+1}^{h}}{\delta} \\
\bar{u}_{0}^{h}=u_{0}^{h}
\end{gathered}
$$

Also the solutions, stability and convergency analysis of the original Algorithm BE method for SMHD was presented comprehensively in [5]. This study contains the following examinations. In section 2 , some necessary definitions and lemmas which are referred in [19] are given. In section 3 , the stability of SMHDNTRM with BE method is presented. In Section 4, numerical examples are examined to explain the theoretical results. The $\mathrm{BE}$ and CN methods for SMHD and BE method for SMHDLTRM are compared based on the test results. In the last section the conclusions are given in the and discussed. 


\section{Notation and preliminaries}

$\mathrm{L}^{2}$-norm and inner product are denoted by $(. .$.$) and \|$. respectively. Then similarly, the $W_{p}^{k}(\Omega)$-norm and the $W_{p}^{k}(\Omega)$-semi-norm are denoted by $\|\cdot\|_{p, k}:=\|\cdot\|_{W_{p}^{k}(\Omega)}$ and |. $\left.\right|_{W_{p}^{k}(\Omega)}$, respectively. For $\mathrm{p}=2, H^{k}(\Omega):=W_{2}^{k}(\Omega)$ and it is denoted that $\|\cdot\|_{k}$ and $|.|_{k}$ for the corresponding norm and semi-norm. All definitions, inequalities, lemmas and their proofs are referred in [19]. The pressure, velocity and electric potential spaces are presented by

$$
\begin{aligned}
Q & :=\left\{q \in L^{2}(\Omega): \int_{\Omega} q=0\right\}, \\
X: & =\left\{v \in H^{1}(\Omega)^{d}:\left.v\right|_{\partial \Omega}=0\right\}, \\
S: & =\left\{\psi \in H^{1}(\Omega):\left.\psi\right|_{\partial \Omega}=0\right\} .
\end{aligned}
$$

respectively. $X^{*}=H^{-1}(\Omega)$ is the closure of $\mathrm{L}^{2}(\Omega)$ in $\|\cdot\|_{-1}$, where

$$
\|f\|_{-1}:=\sup _{v \in X} \frac{(f, v)}{\|\nabla v\|}
$$

Let $L^{q}\left(0, T ; W_{p}^{k}(\Omega)\right)$ denote the space

$$
\begin{aligned}
& L^{q}\left(0, T ; W_{p}^{k}(\Omega)\right) \\
& =\left\{\begin{array}{c}
v:(0, T) \rightarrow W_{p}^{k}(\Omega): v \text { is measurable } \\
\text { and } \int_{0}^{T}\|v(t)\|_{W_{p}^{k}(\Omega)}^{q} d t<\infty
\end{array}\right.
\end{aligned}
$$

endowed with the norm

$$
\|v\|_{L^{q}\left(0, T ; W_{p}^{k}(\Omega)\right)}:=\left(\int_{0}^{T}\|v(t)\|_{W_{p}^{k}(\Omega)}^{q} d t\right)^{1 / q} .
$$

Write $L^{q}\left(W_{p}^{k}\right)=L^{q}\left(0, T ; W_{p}^{k}(\Omega)\right)$ and $\quad C^{m}\left(W_{p}^{k}\right)=$ $C^{m}\left([0, T] ; W_{p}^{k}(\Omega)\right)$. For $v(x, t)$ and $1 \leq p \leq \infty$, we introduce

$$
\begin{aligned}
\|v\|_{\infty, k} & :=\operatorname{esssup}_{0<t<T}\|v(t, \cdot)\|_{k}, \\
\|v\|_{p, k} & :=\left(\int_{0}^{T}\|v(t, \cdot)\|_{k}^{p} d t\right)^{1 / p} .
\end{aligned}
$$

Let $V$ be the divergence free subspace of $\mathrm{X}$, i.e.

$$
V=\{v \in X:(q, \nabla \cdot v)=0, \forall q \in Q\} .
$$

Definition 1 Skew-symmetric trilinear form $b^{*}: X \times X \times$ $X \rightarrow \mathbb{R}$ is defined as

$$
b^{*}(u, v, w)=\frac{1}{2}(u \cdot \nabla v, w)-\frac{1}{2}(u \cdot \nabla w, v) .
$$

Lemma 1 Let $\Omega \subset \mathbb{R}^{2}$ or $\mathbb{R}^{3}$. For all $u, v, w \in X$

$$
b^{*}(u, v, w) \leq C(\Omega)\|\nabla u\|\|\nabla v\|\|\nabla w\|
$$

and

$$
b^{*}(u, v, w) \leq C(\Omega)\|u\|^{(1 / 2)}\|\nabla u\|^{(1 / 2)}\|\nabla v\|\|\nabla w\| .
$$

Lemma 2 (Discrete Gronwall Lemma) Let $\Delta t, B, a_{n}, b_{n}, c_{n}, d_{n}$ for integers $n \geq 0$ be nonnegative numbers such that

$$
\begin{aligned}
a_{l}+\Delta t \sum_{n=0}^{l} b_{n} \leq & \Delta t \sum_{n=0}^{l} d_{n} a_{n}+\Delta t \sum_{n=0}^{l} c_{n}+B \text { for } l \\
& \geq 0 .
\end{aligned}
$$

Suppose that $\Delta t d_{n}<1$ for each $\mathrm{n}$. Then,

$$
\begin{aligned}
a_{l}+\Delta t \sum_{n=0}^{l} b_{n} \leq & \left(\Delta t \sum_{n=0}^{l} c_{n}\right. \\
& +B) \exp \left(\Delta t \sum _ { n = 0 } ^ { l } \left(\left(d_{n}\right)\right.\right. \\
& \left.\left./\left(1-\Delta t d_{n}\right)\right)\right) \text { for } l \geq 0 .
\end{aligned}
$$

Let $\tau^{h}$ be a uniformly regular triangulation of $\Omega$ and

$$
h=\sup _{K \in \tau^{h}} d(K) \text {. }
$$

Let $X^{h} \subset X, Q^{h} \subset Q$ and $S^{h} \subset S$ be a conforming velocitypressure-potential mixed finite element space which satisfy the $L B B^{h}$ condition,

$$
\inf _{q \in Q^{h}} \sup _{v \in X^{h}} \frac{(q, \nabla \cdot v)}{\left(|v|_{1}\|q\|\right)} \geq C>0 .
$$

Let

$$
V^{h}=v \in X^{h}: \int_{\Omega} q \nabla \cdot v=0 \forall q \in Q^{h}
$$

As known $V^{h} \not \subset V$. The velocity-pressure spaces which satisfy the $L B B^{h}$ condition and the following approximation properties;

$$
\begin{gathered}
\inf _{v \in X^{h}}\|u-v\|_{1} \leq C h^{k+1}\|u\|_{k+1}, u \in H^{k+1}(\Omega)^{d} \\
\inf _{v \in X^{h}}\|u-v\|_{1} \leq C h^{k}\|u\|_{k+1}, u \in H^{k+1}(\Omega)^{d} \\
\inf \|\varphi-\psi\|_{1} \leq C h^{r}\|\varphi\|_{r+1}, \varphi \in H^{r+1}(\Omega) \\
\inf _{\mathrm{r} \in Q^{\mathrm{h}}}\|p-r\| \leq C h^{s+1}\|p\|_{s+1}, p \in H^{s+1}(\Omega)
\end{gathered}
$$


If $L B B^{h}$ condition is assured, the inequality presented below will be used in the proof. For all $u \in V$ :

$$
\text { inf } f_{v \in V^{h}}\|\nabla(u-v)\| \leq C(\Omega) i n f_{v \in X^{h}}\|\nabla(u-v)\| .
$$

\section{Stability of the Backward-Euler Method for} SMHDNTRM

Theorem 1 (Stability) The solution $u^{h}$ obtained by Algorithm 1 is unconditionally stable and satisfies the following unconditional stability bound

$$
\begin{gathered}
\left\|u_{M}^{h}\right\|^{2}+N \kappa \delta\left\|\bar{u}_{M}^{h}\right\|^{2}+\sum_{n=0}^{M-1}\left\|u_{n+1}^{h}-u_{n}^{h}\right\|^{2} \\
+N \delta \kappa \sum_{n=0}^{M-1}\left\|\bar{u}_{n+1}^{h}-\bar{u}_{n}^{h}\right\|^{2} \\
+\left((2 \Delta t N) /\left(M^{2}\right)\right) \sum_{n=1}^{M-1}\left\|\nabla u_{n+1}^{h}\right\|^{2} \\
+2 \Delta t N \sum_{n=0}^{M-1}\left\|j_{n+1}^{h}\right\|^{2}+2 N \delta \kappa \sum_{n=0}^{M-1}\left\|\omega_{n+1}^{h}-\bar{\omega}_{n+1}^{h}\right\|^{2} \\
\leq\left\|u^{0 h}\right\|^{2}+N \kappa \delta\left\|u_{0}^{h}\right\|^{2}+2 \Delta t M^{2} \sum_{n=0}^{M-1}\left\|f_{n+1}\right\|_{-1}^{2}
\end{gathered}
$$

and also

$$
\max _{0 \leq n \leq K-1}\left\|\nabla \varphi_{n+1}^{h}\right\|^{2} \leq B^{2}\left\|u^{h}\right\|_{L^{\infty}\left(L^{2}\right)}^{2}
$$

or

$$
\begin{aligned}
\max _{0 \leq n \leq M-1}\left\|\nabla \varphi_{n+1}^{h}\right\|^{2} & \\
& \leq B^{2}\left(\left\|u_{0}^{h}\right\|^{2}\right. \\
& \left.+M^{2} N \Delta t \sum_{i=1}^{M-1}\left\|f_{n+1}\right\|_{-1}^{2}\right)
\end{aligned}
$$

where

$$
B:=\|B\|_{L^{\infty}\left(L^{\infty}\right)}
$$

Proof Putting $v^{h}=u_{n+1}^{h}, q^{h}=p_{n+1}^{h}, \psi^{h}=\varphi_{n+1}^{h} \quad$ into Algorithm 1 gives as

$$
\begin{gathered}
N^{-1}\left(\left(\left(\left(u_{n+1}^{h}-u_{n}^{h}\right) /(\Delta t)\right), u_{n+1}^{h}\right)\right. \\
\left.+b^{*}\left(u_{n+1}^{h}, u_{n+1}^{h}, u_{n+1}^{h}\right)\right) \\
+M^{-2}\left(\nabla u_{n+1}^{h}, \nabla u_{n+1}^{h}\right) \\
-\left(p_{n+1}^{h}, \nabla \cdot u_{n+1}^{h}\right)+\left(-\nabla \varphi_{n+1}^{h}\right. \\
\left.+u_{n+1}^{h} \times B_{n+1}, u_{n+1}^{h} \times B_{n+1}\right)+ \\
\kappa\left(\left|u_{n}^{h}-\bar{u}_{n}^{h}\right|\left(u_{n+1-} \bar{u}_{n+1}\right), u_{n+1}^{h}\right)=\left(f_{n+1}, u_{n+1}^{h}\right) \\
\left(\nabla \cdot u_{n+1}^{h}, p_{n+1}^{h}\right)=0, \forall q^{h} \in Q^{h} \\
\left(-\nabla \varphi_{n+1}^{h}+u_{n+1}^{h} \times B_{n+1},-\nabla \varphi_{n+1}^{h}\right)=0
\end{gathered}
$$

$$
\begin{aligned}
\frac{\bar{u}_{n+1}^{h}-\bar{u}_{n}^{h}}{\Delta t} & =\frac{u_{n+1}^{h}-\bar{u}_{n+1}^{h}}{\delta} \\
\bar{u}_{0}^{h} & =u_{0}^{h}
\end{aligned}
$$

Since $j_{n+1}^{h}=-\nabla \varphi_{n+1}^{h}+u_{n+1}^{h} \times B$ and adding (24) and (25) we obtain (skew symmetry property is used);

$$
\begin{aligned}
N^{-1}\left(\left(\left(u_{n+1}^{h}-u_{n}^{h}\right) /(\Delta t)\right), u_{n+1}^{h}\right)+M^{-2}\left\|\nabla u_{n+1}^{h}\right\| \\
+\left\|j_{n+1}^{h}\right\|^{2} \\
+\kappa\left(\left|u_{n}^{h}-\bar{u}_{n}^{h}\right|\left(u_{n+1}^{h}-\bar{u}_{n+1}^{h}\right), u_{n+1}^{h}\right) \\
=\left(f_{n+1}, u_{n+1}^{h}\right)
\end{aligned}
$$

where

$$
\begin{aligned}
& \kappa\left(\left|u_{n}^{h}-\bar{u}_{n}^{h}\right|\left(u_{n+1}^{h}-\bar{u}_{n+1}^{h}\right), u_{n+1}^{h}\right) \\
& =\kappa\left(\left|u_{n}^{h}-\bar{u}_{n}^{h}\right|\left(u_{n+1}^{h}-\bar{u}_{n+1}^{h}\right), u_{n+1}^{h}\right. \\
& \left.+\bar{u}_{n+1}^{h}-\bar{u}_{n+1}^{h}\right) \\
& =\kappa\left(| u _ { n } ^ { h } - \overline { u } _ { n } ^ { h } | \left(\begin{array}{l}
\left.\left.u_{n+1}^{h}-\bar{u}_{n+1}^{h}\right), \bar{u}_{n+1}^{h}\right) \\
+\kappa\left(\left|u_{n}^{h}-\bar{u}_{n}^{h}\right|\left(u_{n+1}^{h}-\bar{u}_{n+1}^{h}\right), u_{n+1}^{h}\right. \\
\left.-\bar{u}_{n+1}^{h}\right)
\end{array}\right.\right.
\end{aligned}
$$

and

$$
\begin{gathered}
\kappa\left(\left|u_{n}^{h}-\bar{u}_{n}^{h}\right|\left(u_{n+1}^{h}-\bar{u}_{n+1}^{h}\right), u_{n+1}^{h}-\bar{u}_{n+1}^{h}\right) \\
=\kappa\left\|\sqrt{\left(\left|u_{n}^{h}-\bar{u}_{n}^{h}\right|\right)}\left(u_{n+1}^{h}-\bar{u}_{n+1}^{h}\right)\right\|^{2} \\
=\kappa\left\|\sqrt{\left(\left|u_{n}^{h}-\bar{u}_{n}^{h}\right|\right)} u_{n+1}^{h}-\sqrt{\left(\left|u_{n}^{h}-\bar{u}_{n}^{h}\right|\right)} \bar{u}_{n+1}^{h}\right\|^{2}
\end{gathered}
$$

Denoting $\quad \omega_{n+1}^{h}=\sqrt{\left(\left|u_{n}^{h}-\bar{u}_{n}^{h}\right|\right)} u_{n+1}^{h} \quad$ and $\quad \bar{\omega}_{n+1}^{h}=$ $\sqrt{\left(\left|u_{n}^{h}-\bar{u}_{n}^{h}\right|\right)} \bar{u}_{n+1}^{h}$ in (29) gives as

$$
\begin{gathered}
N^{-1}\left(\left(\frac{u_{n+1}^{h}-u_{n}^{h}}{\Delta t}\right), u_{n+1}^{h}\right)+M^{-2}\left\|\nabla u_{n+1}^{h}\right\|^{2} \\
+\left\|j_{n+1}^{h}\right\|^{2} \\
+\kappa\left\|\omega_{n+1}^{h}-\bar{\omega}_{n+1}^{h}\right\|^{2} \\
+\kappa\left(\left|u_{n}^{h}-\bar{u}_{n}^{h}\right|\left(u_{n+1}^{h}-\bar{u}_{n+1}^{h}\right), \bar{u}_{n+1}^{h}\right) \\
=\left(f_{n+1}, u_{n+1}^{h}\right)
\end{gathered}
$$

where

$$
\begin{gathered}
\left(u_{n+1}^{h}-u_{n}^{h}, u_{n+1}^{h}\right)=\left(\left(u_{n+1}^{h}, u_{n+1}^{h}\right)-\left(u_{n}^{h}, u_{n+1}^{h}\right)\right) \\
\left(u_{n}^{h}, u_{n+1}^{h}\right)=\frac{\left\|u_{n+1}^{h}\right\|^{2}+\left\|u_{n}^{h}\right\|^{2}-\left\|u_{n+1}^{h}-u_{n}^{h}\right\|^{2}}{2} \\
\left(\left|u_{n}^{h}-\bar{u}_{n}^{h}\right|\left(u_{n+1}^{h}-\bar{u}_{n+1}^{h}\right), u_{n+1}^{h}-\bar{u}_{n+1}^{h}\right) \\
=\left(| u _ { n } ^ { h } - \overline { u } _ { n } ^ { h } | \left(u_{n+1}^{h}\right.\right. \\
\left.\left.-\bar{u}_{n+1}^{h}\right), \frac{\delta}{\Delta t}\left(\bar{u}_{n+1}^{h}-\bar{u}_{n}^{h}\right)\right) \\
\left(\bar{u}_{n+1}^{h}-\bar{u}_{n}^{h}, \bar{u}_{n+1}^{h}\right) \\
=\frac{\left\|\bar{u}_{n+1}^{h}-\bar{u}_{n}^{h}\right\|^{2}+\left\|\bar{u}_{n+1}^{h}\right\|^{2}-\left\|\bar{u}_{n}^{h}\right\|^{2}}{2}
\end{gathered}
$$

Now let's put the previous terms into (30) 


$$
\begin{gathered}
\frac{N^{-1}}{\Delta t}\left(\frac{\left\|u_{n+1}^{h}\right\|^{2}-\left\|u_{n}^{h}\right\|^{2}+\left\|u_{n+1}^{h}-u_{n}^{h}\right\|^{2}}{2}\right) \\
+M^{-2}\left\|\nabla u_{n+1}^{h}\right\|^{2} \\
+\left\|j_{n+1}^{h}\right\|^{2}+\kappa\left\|\omega_{n+1}^{h}-\bar{\omega}_{n+1}^{h}\right\|^{2}+\frac{\kappa \delta}{\Delta t}\left(\frac{\left\|\bar{u}_{n+1}^{h}-\bar{u}_{n}^{h}\right\|^{2}}{2}\right) \\
+\frac{\kappa \delta}{\Delta t} \frac{\left\|\bar{u}_{n+1}^{h}\right\|^{2}}{2}-\frac{\kappa \delta}{\Delta t} \frac{\left\|\bar{u}_{n}^{h}\right\|^{2}}{2}=\left(f_{n+1}, u_{n+1}^{h}\right)
\end{gathered}
$$

multiply by $2 \Delta t N$ and summing from $n=1$ to $M-1$ gives the desired result. Similarly, setting $\psi=\varphi_{n+1}^{h}$ in (25) with Cauchy-Schwarz and Young's inequalities are used to bound the force term. Then;

$$
\begin{gathered}
\left\|\nabla \varphi_{n+1}^{h}\right\|^{2} \leq\left\|u_{n+1}^{h} \times B_{n+1}\right\|^{2} \leq B^{2}\left\|u_{n+1}^{h}\right\|^{2} \\
\leq B^{2}\left\|u^{h}\right\|_{L^{\infty}\left(L^{2}\right)}^{2} .
\end{gathered}
$$

Apply (22) to (31) to prove (23).

\section{Numerical Examples}

In this section SMHDNTRM that is introduced by Algorithm 1 is tested with some numerical examples. The $\mathrm{BE}$ and $\mathrm{CN}$ methods for SMHD and BE method for SMHDLTRM are compared based on the test results. The linear time relaxation term $\kappa(u-\bar{u})$ is added to SMHD and its introduced as SMHDLTRM in [20]. In the first example a problem which has an exact solution is considered. The second example has the same exact solution but the initial conditions are different from Example 1. These conditions make the problem blow up with $\mathrm{CN}$ method. The FreeFem++ is used for all calculations. T is final time, $\Delta \mathrm{t}$ is time step, $\mathrm{M}$ is Hartmann Number, Re is Reynolds Number and $h$ is mesh size for all examples.

Example 1 Let $\Omega=[0, \pi]^{2}, t_{0}=0, T=1$ and $B=(0,0,1)$. Then, the true solution of $(5)$ for $(u, p, \varphi)$ is given below [4];

$$
\begin{gathered}
u(x, y, t)=\left(-\frac{\partial \psi(x, y)}{\partial y}, \frac{\partial \psi(x, y)}{\partial x}\right) e^{-5 t} \\
\varphi(x, y, t)=\left(\psi(x, y)+x^{2}-y^{2}\right) e^{-5 t} \\
p(x, y, t)=0
\end{gathered}
$$

where $\psi(x, y)=\cos (2 x) \cos (2 y)$ and $f$ and $\left.u\right|_{\partial \Omega}$ are obtained from the true solution. The convergency of the method is analyzed for different values of $\kappa$ and $\Delta t$, selecting $R e=25, M=20, T=1, h=1 / 50, \delta=1 / 10$ in here. The results are given in Table $1-4$. In Table $1, \mathrm{BE}$ method for SMHD is presented with $\kappa=0$. As seen from the Table 1 , while $\kappa=1$, the errors of SMHDNTRM are smaller than BE method for SMHDLTRM and SMHD. It is also bigger than CN method for SMHD, since the order of the CN method is two. In Table 2, the convergences rates of SMHD with CN and BE methods, SMHDLTRM and SMHDNTRM with BE method are compared. In Table 3 and 4, values of $p$ and $\varphi$ are compared with SMHD, SMHDLTRM and SMHDNTRM for different values of $\Delta t$ It seen from these tables, the pressure and potential errors are smaller than the other methods with SMHDNTRM in some cases.

Table 1. Velocity errors of SMHD, SMHDLTRM and SMHDNTRM for Example 1.

\begin{tabular}{ccccc}
\hline \multicolumn{5}{c}{$\left\|u-u_{n}^{h}\right\|$} \\
\hline$\Delta t$ & CN-SMHD & $\begin{array}{c}\text { BE-SMHD } \\
(\kappa=0)\end{array}$ & $\begin{array}{c}\text { BE- } \\
\text { SMHDLTRM } \\
(\kappa=1)\end{array}$ & $\begin{array}{c}\text { BM- } \\
\text { SMDNTRM } \\
(\kappa=1)\end{array}$ \\
\hline $1 / 10$ & 0.0184967 & 0.50428 & 0.497796 & 0.382574 \\
$1 / 20$ & 0.0046309 & 0.26432 & 0.261351 & 0.124133 \\
$1 / 40$ & 0.0011447 & 0.13523 & 0.133857 & 0.0214929 \\
$1 / 80$ & 0.0002734 & 0.06838 & 0.0677267 & 0.0836249 \\
\hline
\end{tabular}

Table 2. Convergence rates of SMHD, SMHDLTRM and SMHDNTRM for Example 1.

Convergence Rates

\begin{tabular}{ccccc}
\hline$\Delta t$ & $\begin{array}{c}\text { CN- } \\
\text { SMHD }\end{array}$ & $\begin{array}{c}\text { BE-SMHD } \\
(\kappa=0)\end{array}$ & $\begin{array}{c}\text { BE-SMHDLTRM } \\
(\kappa=1)\end{array}$ & $\begin{array}{c}\text { BE-SMHDNTRM } \\
(\kappa=1)\end{array}$ \\
\hline $1 / 10$ & & & & \\
$1 / 20$ & 1.998 & 0.932 & 0.930 & 1.624 \\
$1 / 40$ & 2.016 & 0.967 & 0.965 & 1.960 \\
$1 / 80$ & 2.066 & 0.984 & 0.983 & 2.530 \\
\hline
\end{tabular}

Table 3. Potential errors of SMHD, SMHDLTRM and SMHDNTRM for Example 1.

\begin{tabular}{cccc}
\hline \multicolumn{3}{c}{$\left\|\varphi-\varphi_{n}^{h}\right\|$} \\
\hline$\Delta t$ & $\begin{array}{c}\text { BE-SMHD } \\
(\kappa=0)\end{array}$ & $\begin{array}{c}\text { BE-SMHDLTRM } \\
(\kappa=1)\end{array}$ & $\begin{array}{c}\text { BE-SMHDNTRM } \\
(\kappa=1)\end{array}$ \\
\hline $1 / 10$ & 0.277553 & 0.146518 & 0.214342 \\
$1 / 20$ & 0.145644 & 0.144009 & 0.071731 \\
$1 / 40$ & 0.0745424 & 0.0737849 & 0.00545451 \\
$1 / 80$ & 0.0376974 & 0.0373372 & 0.0420529 \\
$1 / 160$ & 0.0189512 & 0.0187762 & 0.0612152 \\
\hline
\end{tabular}

Table 4. Pressure errors of SMHD, SMHDLTRM and SMHDNTRM for Example 1.

\begin{tabular}{cccc}
\hline \multicolumn{3}{c}{$\left\|p-p_{n}^{h}\right\|$} \\
\hline$\Delta t$ & $\begin{array}{c}\text { BE-SMHD } \\
(\kappa=0)\end{array}$ & $\begin{array}{c}\text { BE-SMHDLTRM } \\
(\kappa=1)\end{array}$ & $\begin{array}{c}\text { BE-SMHDNTRM } \\
(\kappa=1)\end{array}$ \\
\hline $1 / 10$ & 0.00516417 & 0.273995 & 0.00311038 \\
$1 / 20$ & 0.00157142 & 0.0015402 & 0.000998216 \\
$1 / 40$ & 0.000503184 & 0.000495084 & 0.0010316 \\
$1 / 80$ & 0.000182351 & 0.000179983 & 0.00109324 \\
\hline
\end{tabular}




\begin{tabular}{llll}
\hline $1 / 160$ & $7.56518 \mathrm{e}-5$ & $7.4825 \mathrm{e}-5$ & 0.00113279 \\
\hline
\end{tabular}

Example 2 Let $\Omega=[0, \pi]^{2}, t_{0}=0, T=1,2$ and 5 . $B=$ $(0,0,1)$. In this example, SMHD equation is solved both CN and BE methods, SMHDLTRM and SMHDNTRM are solved with $\mathrm{BE}$ method for $h=1 / 10$ and $\Delta t=1 / 100, R e=$ $6766, M=20, \delta=1 / 10$ and different values of $\kappa$ and $T$. The boundary condition on $\partial \Omega$ is inhomogeneous Dirichlet: $u_{h}=u$. The initial data is given by

$$
\begin{gathered}
u_{0}(x, y)=(y,-x, 0) \\
\varphi_{0}(x, y)=x y
\end{gathered}
$$

and $f$ is the same as in Example 1.

In this example, while CN method for SMHD is blow up, BE method is convergent [5]. We consider SMHDLTRM and SMHDNTRM for this example to determine how the linear time filter effects to the solutions. As seen from the Table 5, velocity errors of SMHDNTRM are smaller than SMHD and SMHDLTRM for all values of $\kappa$. Also, when values of $\kappa$ increases, the errors decrease for different values of T. From here, in case the classical methods (CN or BE methods) are failed, linear or nonlinear time relaxation models can be applied to the problem to get more accurate solutions.

In Table 6, selecting $h=1 / 10$ and $\Delta t=1 / 10$, the velocity errors are compared for different values of $\delta$ when $\kappa=$ 10 and for different values of $\kappa$ when $\delta=0.1$ for BE solutions of SMHDLTRM and SMHDNTRM. When Table 6 is examined; it is observed that while $\kappa=10, \delta$ values are increasing and similarly for $\delta=0.1, \kappa$ values are increasing. As a result velocity errors are decreasing.

\section{Conclusion}

In this paper, we have analyzed SMHDNTRM with BE method. The BE method for SMHD and its numerical analysis are already given in [5], for SMHDTRM and its numerical analysis are already given in [20] comprehensively by Yüksel and Yaman. In this work, the nonlinear differential time filter $\kappa(|u-\bar{u}|(u-\bar{u}))$ term is added to SMHD equations to obtain more accurate solutions. The stability analysis of the SMHDNTRM with $\mathrm{BE}$ method are investigated. The present method is unconditionally stable from Theorem 1 . In the last section, numerical tests are given for effectiveness of present method. The solutions of the present method are compared with both BE and CN methods for SMHD and BE method for SMHDLTRM. As seen from the numerical examples, the nonlinear differential filter may be relaxed the time step of the problem, thus SMHDNTRM can be used when the classical methods (BE-CN) does not work for SMHD to get more accurate solutions.

\section{Acknowledgement}

This paper has been granted by the Mugla Sitki Kocman University Research Projects Coordination Office. Project Grant Number: 17/225 and title "Basitleştirilmiş Manyetohidrodinamik (MHD) denklemlerinin sonlu elemanlar metoduyla çözümleri için geliştirilen zaman rahatlatma modelleri".

Table 5. Velocity errors of SMHD, SMHDLTRM and SMHDNTRM for Example 2.

\begin{tabular}{ccccccccc}
\hline \multicolumn{3}{c}{ BE-SMHDLTRM } & \multicolumn{3}{c}{ BE-SMHDNTRM } \\
\hline $\mathrm{T}$ & $\mathrm{CN}$ & $\mathrm{BE}(\kappa=0)$ & $\kappa=1$ & $\kappa=10$ & $\kappa=100$ & $\kappa=1$ & $\kappa=10$ & $\kappa=100$ \\
1 & 4.5372 & 3.17034 & 3.16741 & 3.14119 & 2.89017 & 2.46409 & 1.0276 & 0.82574 \\
2 & Blow & 2.52362 & 2.51909 & 2.47887 & 2.12973 & 1.66875 & 0.41271 & 0.327109 \\
& Up & & & & & & 0.155908 & 0.124238 \\
5 & Blow & 1.43754 & 1.43525 & 1.40639 & 0.955979 & 0.738058 & 0.1598 \\
& Up & & & & & & & \\
\hline
\end{tabular}

Table 6. Velocity errors for SMHDLTRM and SMHDNTRM for Example 2, $\Delta t=1 / 10, h=1 / 10$.

\begin{tabular}{cccccccc}
\hline \multicolumn{3}{c}{ BE-SMHDLTRM } & \multicolumn{3}{c}{ BE-SMHDNTRM } \\
\hline \multicolumn{1}{c}{$\kappa=10$} & \multicolumn{2}{c}{$\delta=0.1$} & \multicolumn{1}{c}{$\kappa=10$} & \multicolumn{1}{c}{$\delta$} \\
\hline$\delta$ & $\left\|u-u_{h}\right\|$ & $\kappa$ & $\left\|u-u_{h}\right\|$ & $\delta$ & $\left\|u-u_{h}\right\|$ & $\kappa$ & $\left\|u-u_{h}\right\|$ \\
0 & 3.17034 & 0 & 3.17034 & 0 & 3.17034 & 0 & 3.17034 \\
$10^{-3}$ & 2.7954 & $10^{-1}$ & 2.79523 & $10^{-3}$ & 0.0062226 & $10^{-1}$ & 0.00635579 \\
$10^{-2}$ & 2.77838 & 1 & 2.77687 & $10^{-2}$ & 0.00520223 & 1 & 0.00606934 \\
$10^{-1}$ & 2.59849 & $10^{1}$ & 2.59894 & $10^{-1}$ & 0.0139712 & $10^{1}$ & 0.0139712
\end{tabular}




\section{References}

[1] Davidson, P. A., An Introduction to Magnetohydrodynamics. Cambridge University Press, United Kingdom, 2001.

[2] Peterson, J. S., "On the finite element approximation of incompressible flows of an electrically conducting fluid", Numerical Methods for Partial Differential Equations, vol.4, no.1, pp. 57-68, 1988.

[3] Layton, W., Tran, H. and Trenchea C., "Stability of partitioned methods for magnetohydrodynamics flows at small magnetic Reynolds numbers", Contemporary Mathematics, vol. 586, pp. 231- 238, 2013.

[4] Yuksel, G. and Ingram, R., "Numerical analysis of a finite element, Crank-Nicolson discretization for MHD flow at small magnetic Reynolds number", International Journal of Numerical Analysis and Modeling, vol.10, no.1, pp. 74-98, 2013.

[5] Yuksel, G. and Isik, O. R., "Numerical analysis of Backward-Euler discretization for simplified magnetohydrodynamic flows", Applied Mathematical Modelling. Simulation and Computation for Engineering and Environmental Systems, vol. 39, no. 7, 1889-1898, 2015.

[6] Layton, W., Tran, H. and Trenchea C., "Numerical analysis of two partitioned methods for uncoupling evolutionary MHD flows", Numerical Methods for Partial Differential Equations, vol. 30, no. 4, pp. 10831102, 2014.

[7] Rong, Y., Hou, Y. and Zhang, Y., "Numerical analysis of a second order algorithm for simplified magnetohydrodynamic flows", Advances in Computational Mathematics, vol. 43, pp. 823-848, 2017.

[8] Stolz, S., Adams, N. A. and Kleiser, L., " The approximate deconvolution model for LES of compressible flows and its application to shockturbulent-boundary layer interaction", Physics of Fluids, vol. 13, no. 10, pp. 2985-3001, 2001.

[9] Stolz, S., Adams, N. A. and Kleiser, L., "An approximate deconvolution model for large eddy simulation with application to wall-bounded flows", Physics of Fluids, vol. 13, no.4, pp. 997-1014, 2001.

[10] Adams, N. A., Stolz, S., Deconvolution methods for subgrid-scale approximation in LES, Modern
Simulation Strategies for Turbulent Flow, R. T. Edwards, 2001.

[11] Rosenau, P., "Extending hydrodynamics via the regularization of the Chapman--Enskog expansion", Physical review. A, General physics, vol. 40, no. 12, pp. 7193-7196, 1989.

[12] Schochet, S. and Tadmor E., The regularized Chapman--Enskog expansion for scalar conservation laws, Archive for Rational Mechanics and Analysis, vol. 119, pp. 95-107, 1992.

[13] Breckling, S., Neda, M. and Hill, T., "A Review of Time Relaxation Methods", Fluids, vol. 2, no. 3, pp. 40-59, 2017.

[14] Pakzad, A., "On the long time behavior of time relaxation model of fluids", Physica D: Nonlinear Phenomena, vol. 408, pp. 1-6, 2020.

[15] Pruett, C.D., et al., The temporally filtered Navier-Stokes equations: properties of the residual-stress, Technical Report, National Science Foundation; United States, 2003.

[16] Layton, W. and Neda, M., "Truncation of scales by time relaxation", Journal of Mathematical Analysis and Applications, vol. 325, no. 2, pp. 788-807, 2007.

[17] Isik, O. R., Yüksel, G. and Demir, B., "Analysis of second order and unconditionally stable BDF2-AB2 method for the Navier-Stokes equations with nonlinear time relaxation", Numerical Methods for Partial Differential Equations, vol. 34, pp. 2060-2078, 2018.

[18] Yaman, M. H., Time Relaxation Models for Simplified MagnetoHydroDynamics Equations by Using Finite Element Method, M.Sc. Thesis, Grad. Sch. Nat. Appl. Sci. 2018.

[19] Layton, W., Introduction to the Numerical Analysis of Incompressible Viscous Flows, SIAM, Philadelphia, 2008.

[20] Yüksel, G. and Yaman, M. H., "Numerical Analysis of Backward-Euler Method for Simplified MagnetoHydroDynamics (SMHD) with Linear Time Relaxation", Turkish Journal of Mathematics and Computer Science, vol. 13, no. 1, pp. 145-161, 2021.

[21] Cibik, A., Eroglu, F.G. \& Kaya, S. Analysis of Second Order Time Filtered Backward Euler Method for MHD Equations. J Sci Comput 82, 38, 2020. 